\title{
Microvascular decompression as a surgical management for trigeminal neuralgia: A critical review of the literature
}

\author{
Serdar Kabatas, S. Baki Albayrak' ${ }^{1}$, Tufan Cansever $^{2}$, Kemal T. Hepgul ${ }^{3}$ \\ Department of Neurosurgery, Baskent University, Ankara, ${ }^{1}$ Department of Neurosurgery, Suleyman Demirel University School of \\ Medicine, Isparta, ${ }^{2}$ Department of Neurosurgery, Gulhane Military Medical Academy, Ankara, ${ }^{3}$ Department of Neurosurgery, \\ Istanbul School of Medicine, Istanbul University, Istanbul, Turkey
}

\begin{abstract}
Address for correspondence: Dr. Serdar Kabatas, Department of Neurosurgery, Baskent University, O ymaci Sokak No:7 34662 Altunizade, Istanbul, Turkey.

E-mail: kabatasserdar@ hotmail. com
\end{abstract}

DOI: $10.4103 / 0028-3886.51279$

\begin{abstract}
Abstradt
Trigeminal neuralgia (TN) is a common pain syndrome and is characterized by recurrent episodes of intense lancinating pain in one or more divisions of the trigeminal nerve. Neurovascular compression (NVC) has been considered as the main cause of TN in the root entry zone (REZ) of the trigeminal nerve in the cerebellopontine angle cistern. Microvascular decompression (MVD) is the surgical procedure of choice for the treatment of medically refractory TN. MVD has also been shown to provide pain relief even in patients without visible neurovascular compression. Additionally, it has been accepted that MVD can provide the highest rate of long-term patient satisfaction with the lowest rate of pain recurrence. We did, systematic review of the subject and also our own experiences.
\end{abstract}

Key words: M icrovascular decompression, neurovascular compression, trigeminal neuralgia

\section{Introduction}

Trigeminal neuralgia (TN) is characterized by paroxysmal shock-like pain localized to the innervated area of one or more branches of trigeminal nerve and is due to vascular compression of the trigeminal nerve at the root entry zone (REZ). ${ }^{[1-6]}$ The age of onset is usually between $40-60$ years and seldom in patients younger than 40 years of age. The exception being symptomatic TN due to multiple sclerosis or tumors. Nevertheless, TN does not present a full-blown clinical picture until before the brief episodes of pain become severe or frequent and unresponsive to medication. ${ }^{[7,8]}$ The initial treatment of choice is medical, antiepileptic drugs (AEDs). About a half of patients with TN eventually require surgical intervention for the definitive relief of pain. ${ }^{[9]}$ The surgical treatment modalities include percutaneous ablative procedures and microvascular decompression (MVD). ${ }^{[10]}$ Percutaneous ablative procedures seem to be safe and simple, with fewer serious complications and a high initial success rate. However, the duration of pain-relief is usually for a shorter period, mostly for less than a year and with repeated interventions the period of pain relief may be even shorter. ${ }^{[3,8]}$ In 1934, Dandy hypothesized for the first time that neurovascular compression may be the cause of TN. Gardner supported the hypothesis around 1962, later Jannetta suggested MVD as a surgical procedure for the treatment of TN. Currently, the MVD procedure is perceived as the most effective treatment for $\mathrm{TN}$ with the most satisfactory outcomes.

\section{Etiology}

The International Association for the Study of Pain (IASP) defines TN as "a sudden, usually unilateral, severe, brief, stabbing, recurrent episodes of pain in the distribution of one or more branches of the trigeminal nerve." The incidence is $3-5$ per $100,000 .{ }^{[11-15]} \mathrm{TN}$ occurs in middle and old ages and it is more frequent in females. ${ }^{[7,16,17]} \mathrm{In}$ general, TN does not involve the V1 and V3 distributions without also affecting the V2 distribution. ${ }^{[18]}$ Numbness may develop in patients with chronic TN or as a sequel of surgical treatment. ${ }^{[19]}$ 


\section{Pathophysiology}

Though there has been much debate over the exact pathophysiology of TN, the neurovascular compression (NVC) theory remains the most plausible explanation. This theory proposes vascular compression of the trigeminal nerve at the point where the nerve leaves the brainstem as the primary pathogenic mechanism for TN. ${ }^{[16,20]}$ More recent and emerging evidence, however, suggests that demyelination of the trigeminal nerve in the REZ plays an important role in the pathophysiology of abnormal neuronal activity and consequent pain perception. ${ }^{[5,10,13,21]}$ In a few cases, TN may be due to the primary demyelinating plaque. Other rare causes include: Infarcts of the brain stem, tumors and other masses of posterior fossa, and rarely amyloid. Once all of these possibilities are ruled out, there remains a small proportion of patients in whom the etiology remains unknown. Histological studies have revealed that compression of the nerve root by an overlying blood vessel results in focal demyelination, with close apposition of demyelinated axons and absence of intervening glial processes. ${ }^{[13]}$ Ectopic action potentials thus generated in the sensory root of the nerve may result in the typical symptoms. Experimental studies have indicated that this anatomical arrangement favors the ectopic generation of spontaneous nerve impulses and their ephaptic conduction to adjacent fibers. ${ }^{[13]}$ Compression of the nerve by an impinging blood vessel is the most common cause of TN. These findings form the rationale for MVD surgery as the treatment for this disorder. ${ }^{[22]}$ On the other hand, some authors still question the NVC theory of TN as such contact of blood vessel loop with trigeminal nerve can be demonstrated in a great majority of the healthy persons. ${ }^{[10,23]}$ In a blinded study, NVC was found with similar frequency on the asymptomatic side in patients with $\mathrm{TN}$, thus questioning the NCV theory. Focal demyelination is not a consistent finding, the observation which has been attributed to the sampling error. ${ }^{[23]}$ Nevertheless, the most common cause of TN is focal compression of the trigeminal nerve root, close to its point of entry into the pons, by aberrant artery or vein. This was first recognized as the cause of TN by Janetta and accounts for $80-90 \%$ of cases of TN. ${ }^{[13]}$

\section{Neuroradiological Evaluation}

Bondt te al., evaluated 288 patients with magnetic resonance imaging (MRI) and magnetic resonance angiography (MRA) for trigeminal deficits and found that $28.5 \%$ of patients had neurovascular compression and $60.2 \%$ of patients had normal neuroradiological findings. ${ }^{[24]}$ But the detection of these abnormalities is highly dependent on the MRI resolution. Using a higher resolution, venous or arterial compression can be differentiated, which may help in predicting the recurrence of TN following MVD. ${ }^{[20]}$ However, NCV may not be found at surgery in all the cases of TN. The reported rates of absence of NCV at operation varied from $4 \%$ to $89 \%$, with an average of $7.5 \% .{ }^{[20]}$ Multiple sclerosis plaque is rare cause of symptomatic TN. Presence of demyelinating plaque, hyperintensity signal in T2-weighted images, along the intrapontine course of the trigeminal pathways is a contraindication for MVD. Ferroli et al., reported successful MVD in a patient without multiple sclerosis, despite an intrapontine trigeminal lesion. ${ }^{[25]}$

\section{Treatment Options}

Many drugs have been tried in TN. Carbamazepine is the first line of treatment. About $70 \%$ of patient with TN will have good initial pain control with carbamazepine. ${ }^{[26]}$ Most of the remaining $30 \%$, of patients will have initial satisfactory response to other pain controlling medications. ${ }^{[27]}$ Unfortunately, with conventional medical therapies, the mean time of recurrence of symptoms is approximately one year. ${ }^{[28]}$ Other issues associated with drug therapy include: Drug tolerance, warring of drug effect, and serious acute and chronic drug adverse events. The next options for symptomatic relief for patient refractory to medical therapy are invasive and surgical procedures. ${ }^{[12]}$

Various invasive therapeutic methods, including injection of ethyl alcohol or butyl alcohol into the ganglion, glycerol injection into the trigeminal cistern, peripheral nerve divisions, as well as radiofrequency thermocoagulation of the preganglionic fiber, have been performed for pain relief. ${ }^{[9,29,30]}$ Currently, percutaneous radiofrequency thermocoagulation, stereotactic radiosurgery, and percutaneous microballoon compression (PMC) are the common ablative therapies for TN. ${ }^{[15,29,31]}$ It seems that percutaneous radiofrequency thermocoagulation therapy is more efficacious in pain relieving, but is associated with a higher complication rate compared with stereotactic radiosurgery. ${ }^{[29]}$ However, the percutaneous trigeminal ganglion approach could be dangerous to a certain extent. For example, it can cause intracranial hemorrhage, carotid injury, carotid-cavernous fistula, and other cranial nerve injuries. ${ }^{[32,33]}$ Encouragingly, neuronavigation can eliminate most of the complications associated with traditional fluoroscopy guided foramen oval haunting and improves the success rate of trigeminal nerve targeting. ${ }^{[34]}$ Although a $75 \%$ success rate for treating TN by radiofrequency was reported 14 years after the creation of gasserian lesions, other studies have found that only about $20 \%$ of patients remained free of pain 6-7 years after this procedure. ${ }^{[9]}$ Regarding results of PMC, Skirving and colleagues reported a recurrence rate of $19.2 \%$ within five years and $31.9 \%$ over the entire follow-up period. ${ }^{[35]}$ Overall, disadvantages of these procedures include injury to the trigeminal nerve, ganglion or root, 
resulting in neurological deficits such as numbness with extended sensory loss, corneal hypesthesia, and deafferentiating pain, which is essentially untreatable.

\section{Microvascular Decompression}

In the earlier years, Jannetta strongly supported the hypothesis of microvascular compression and perfected and popularized the MVD operation for the treatment of TN. ${ }^{[36]}$ Thereafter, Barker et al., emphasized MVD by demonstrating a $70 \%$ cure rate in a 10-year follow-up study ${ }^{\left[{ }^{[9]}\right.}$ However, direct comparisons between various series are hindered by different definitions of operative success regarding the recurrence rate of tic pain after MVD that was done using actuarial methods. ${ }^{[9]}$ Furthermore, it is important to ascertain which artery, vertebral or basilar, is compressing the nerve, as the risk of operating in these patients is higher than in patients where the superior cerebellar artery is the trigger. ${ }^{[37,38]}$

Some studies have shown differences between typical and atypical TN, in about $88 \%$ of patients with typical TN and $56 \%$ of patients with atypical TN a NVC could be demonstrated, compression by a vein is significantly higher in patients with atypical TN than in patients with typical TN. Pain relief by MVD is higher $(\sim 80 \%)$ in patients with typical TN than in patients with atypical TN ( 56\%). Probably this may be the most important prognostic factor in MVD. ${ }^{[38]}$ In these patients, the type of vascular compression may play a role in the recurrence of TN symptoms following MVD. The presence of venous compression is a sign of a poor prognosis. ${ }^{[20]}$

MVD, as a surgical approach, may offer certain definitive benefits. MVD caries a very low risk of anesthesia dolorosa or paresthetic complaints. ${ }^{[39,40]}$ Facial numbness is an occasional sequel of both radiofrequency thermal rhizotomy and glycerol rhizotomy, but it correlates well with pain relief. ${ }^{\left[{ }^{9}\right]}$ Whereas facial numbness is rare following MVD. ${ }^{[31]}$ It is perhaps fair to state that all surgical interventions appear to have a similar short-term efficacy, approximately $80 \%$, but the long-term effects of MVD appear to be superior. ${ }^{[4]}$ Since the benefits of MVD are long lasting and the procedure being more invasive, we believe that MVD is more appropriate for younger patients, whereas ablative therapies are usually preferable in patients older than 70 years. ${ }^{[31,42-44]}$

\section{Complications of Microvascular Decompression}

The complications following MVD include cerebrospinal fluid (CSF) leak, cerebellar injury, hearing loss, and facial palsy. CSF leak, the most frequent complication after MVD surgery, may be associated with intracranial infections such as meningitis. ${ }^{[45,46]}$ The incidence of CSF leak following MVD is in the range of $0.9-12 \% .{ }^{[46]}$
Trigemino-cardiac reflex (TCR) is an important complication during anesthesia and may occur during stimulation of any of the sensory branches of the trigeminal nerve.$^{[47]}$ It is characterized by bradycardia, arterial hypotension, apnea, and gastric hypermotility. TCR is defined as a drop in mean arterial blood pressure (MAP) and heart rate (HR) of more than $20 \%$ of the baseline values before the stimulus and coinciding with the manipulation of the trigeminal nerve. ${ }^{[47-49]}$ In a retrospective study or 28 patientss, the incidence of TCR during MVD was 18\%. Their HR fell $46 \%$ and their MABP $57 \%$ during operative procedures near the trigeminal nerve as compared with levels immediately before the stimulus. After cessation of manipulation, HR and MABP returned to levels before the stimulus. ${ }^{[49]}$ Thus, it is important for both neurosurgeons and anesthesiologists to take all the precautions to prevent this serious complication during MVD.

\section{Reasons for Recurrences Due to MVD}

Factors that have been shown to be significant predict recurrence include: Symptoms lasting for more than eight years, compression of the trigeminal REZ by a vein rather than an artery, and the lack of immediate postoperative pain relief. Female gender also seems to have a higher rate of recurrence ${ }^{[9]}$ Jannetta noted significant vascular compression in $96 \%$ of patients with $\mathrm{TN}$ and in $12 \%$ of them it was due to a vein. ${ }^{[36]}$ However, the reasons for the high recurrences in patients with venous compression are not clear. Re-exploration is often the strategy in patients with recurrence of symptoms. Interestingly, the rate of negative exploration is quite variable, $18-28.5 \%$ depending on the experience of the surgeon. ${ }^{[36]}$ In the retrospective cohort study of MVD by Kalkanis and colleagues the morbidity rates were significantly lower at high-volume hospitals and with high-volume surgeons. The mortality rate was $0.3 \%$, and the rate of discharge other than to home was $3.8 \%$. One or more common complications were seen in $3 \%$ of patients. ${ }^{[31]}$

Lack of immediate postoperative pain relief indicates poor long-term outcomes following MVD. ${ }^{[9]}$ In the study by Barker and colleagues, of the 1182 patients who had MVD, 132 required second operation, 10\% of them within 30 days of first operation. Veins or small arteries were found compressing the nerve. ${ }^{[9]}$ Neurological complications like facial numbness was found more frequently after the second operation. The chance of postoperative pain relief was less following the second MVD surgery ${ }^{[9,19]}$ Minimizing trauma by careful handling of the trigeminal nerve during the operation seems to be the essential component to maintain normal trigeminal nerve function and also to reduce the risk of recurrence. ${ }^{[19]}$ Various studies have shown, of all the currently available surgical methods MVD provides the 
highest rate of long-term satisfaction for the patients and offers the lowest rate of pain recurrence. ${ }^{[50,51]}$

\section{Conclusion}

MVD is an effective surgical treatment for patients with TN refractory to medical treatment. The indications for alternative surgical methods include: (1) severe associated medical co-morbidities contraindicating general anesthesia; (2) persistence of symptoms even after adequate decompression; (3) technical difficulties in safe repositioning of the vessel; and (4) no demonstrable blood vessel compression.

\section{Acknowledgments}

We thank Dr. Yang D. Teng, M.D., Ph.D, Department of Neurosurgery, Harvard Medical School and Brigham and Women's Hospital, Boston, U.S.A, Dr. Aykut Karasu, M.D, Department of Neurosurgery, Istanbul School of Medicine, Istanbul University, Istanbul, Turkey and Dr. Erdinc Civelek, M.D, Department of Neurosurgery, Kastamonu Munif Islamoglu Devlet Hastanesi, Kastamonu, Turkey for their critical evaluation of the manuscript and highly valuable suggestions.

\section{References}

1. Chen JF, Lee ST. Comparison of percutaneous trigeminal ganglion compression and microvascular decompression for the management of trigeminal neuralgia. Clin Neurol Neurosurg 2003;105:203-8.

2. Civelek E, Cansever T, Imer M, Hepgul K, Barlas O. Trigeminal neuralgia and treatment options. Agri 2005;17:19-26.

3. de Siqueira SR, da Nobrega JC, Teixeira MJ, de Siqueira JT. Masticatory problems after balon compression for trigeminal neuralgia: A longitudinal study. J Oral Rehab 2007;34:88-96.

4. Pamir MN, Peker S. Microvascular decompression for trigeminal neuralgia: A long-term follow-up study. Minim Invas Neurosurg 2006;49:342-6.

5. Satoh T, Onoda K, Date I. Preoperative simulation for microvascular decompression in patients with idiopathic trigeminal neuralgia: Visualization with three-dimensional magnetic resonance cisternogram and angiogram fusion imaging: Clinical studies. Neurosurg 2007;60:104-14.

6. Tawk RG, Duffy-Fronckowiak M, Scott BE, Alberico RA, Diaz AZ, Podgorsak MB, et al. Stereotactic gamma knife surgery for trigeminal neuralgia: Detailed analysis of treatment response. J Neurosurg 2005; 102:442-9.

7. Olson S, Atkinson L, Weidmann M. Microvascular decompression for trigeminal neuralgia: Recurrences and complications. J Clin Neurosci 2005;12:787-9.

8. Wilkinson HA. Trigeminal nevre peripheral branch phenol/glycerol injections for tic douloureux. J Neurosurg 1999;90:828-32.

9. Barker FG $2^{\text {nd }}$, Jannetta PJ, Bissonette DJ, Larkins MV, Jho HD. The long-term outcome of microvascular decompression for trigeminal neuralgia. N Engl J Med 1996;334:1077-83.

10. Nurmikko TJ, Eldridge PR. Trigeminal neuralgia-pathophysiology, diagnosis and current treatment. Br J Anaesth 2001;87:117-32.

11. Kanpolat Y, Savas A, Bekar A, Berk C. Percutaneous controlled radiofrequency trigeminal rhizotomy for the treatment of idiopathic trigeminal neuralgia: 25-year experience with 1600 patients. Neurosurgery 2001;48:524-34.

12. Kitt CA, Gruber K, Davis M, Woolf CJ, Levine JD. Trigeminal neuralgia: Opportunities for research and treatment. Pain 2000;85:3-7.

13. Love S, Coakham HB. Trigeminal neuralgia: Pathology and pathogenesis. Brain 2001;124:2347-60.

14. Sweet WH, Wepsic JG. Controlled thermocoagulation of trigeminal ganglion and rootlets for differential destruction of pain fibers, Part I: trigeminal ganglion. J Neurosurg 1974;39:143-56.

15. Taha JM, Tew JM Jr. Comparison of surgical treatments for trigeminal neuralgia: Reevaluation of radiofrequency rhizotomy. Neurosurgery 1996;38:865-71.

16. Chole R, Patil R, Degwekar SS, Bhowate RR. Drug treatment of trigeminal neuralgia: A systematic review of the literature. J Oral Maxillofac Surg 2007;65:40-5.

17. Headache Classification Subcommittee of the International Headache Society: The international classification of headache disorders. Cephalalgia 2004;24:9-160.

18. Eskandar E, Barker FG 2 $2^{\text {nd }}$, Rabinov JD. Case 21-2006: A 61-year-old man with left-sided facial pain. N Engl J Med 2006;355:183-8.

19. Barker FG $2^{\text {nd }}$, Jannetta PJ, Bissonette DJ, Jho HD. Trigeminal numbness and tic relief after microvascular decompression for typical trigeminal neuralgia. Neurosurgery 1997;40:39-45.

20. Kuncz A, Vörös E, Barzó P, Tajti J, Milassin P, Muesi Z, et al. Comparison of clinical symptoms and magnetic resonance angiographic (MRA) results in patients with trigeminal neuralgia and persistent idiopathic facial pain. Medium-term outcome after microvascular decompression of cases with positive MRA findings. Cephalalgia $2006 ; 26: 266-76$.

21. Yoshino N, Akimoto H, Yamada I, Nagaoka T, Tetsumura A, Kurabayashi T, et al. Trigeminal neuralgia: Evaluation of neuralgic manifestation and site of neurovascular compression with 3D CISS MR imaging and MR angiography. Radiology 2003;228:539-45.

22. Jannetta PJ, Abbasy M, Maroon JC, Ramos FM, Albin MS. Etiology and definitive microsurgical treatment of hemifacial spasm: Operative techniques and results in 47 patients. J Neurosurg 1977;47:321-8.

23. Monstad P. Microvascular decompression as a treatment for cranial nerve hyperactive dysfunction: A critical view. Acta Neurol Scand Suppl 2007:187:30-3.

24. de Bondt BJ, Stokroos R, Casselman J. Persistent trigeminal artery associated with trigeminal neuralgia: Hypothesis of neurovascular compression. Diagn Neuroradiol 2007;49:23-6.

25. Ferroli P, Franzini A, Farina L, La Mantia L, Broggi G. Does the presence of a pontine trigeminal lesion represent an absolute contraindication for microvascular decompression in drug resistant trigeminal neuralgia. J Neurol Neurosurg Psychiatry 2002;72:122-3.

26. McQuay H, Carroll D, Jadad AR, Wiffen P, Moore A. Anticonvulsant drugs for management of pain: A systematic review. BMJ 1995;311:1047-52.

27. Merrison AF, Fuller G. Treatment options for trigeminal neuralgia. BMJ 2003;327:1360-1.

28. Zakrzewska JM, Patsalos P. Long-term cohort study comparing medical (oxcarbazepine) and surgical management of intractable trigeminal neuralgia. Pain 2002;95:259-66.

29. Lopez BC, Hamlyn PJ, Zakrzewska JM. Systematic review of ablative neurosurgical techniques for the treatment of trigeminal neuralgia. Neurosurgery 2004;54:973-83.

30. Natarajan M. Percutaneous trigeminal ganglion balloon compression: Experience in 40 patients. Neurol India 2000;48:330-2.

31. Kalkanis SN, Eskandar EN, Carter BS, Barker FG $2^{\text {nd }}$. Microvaseular decompression surgery in the United States, 1996 to 2000: Mortality rates, morbidity rates, and the effects of hospital and surgeon volumes. Neurosurgery 2003;52:1251-61.

32. Gokalp HZ, Kanpolat Y, Tumer B. Carotid-cavernous fistula following percutaneous trigeminal ganglion approach. Clin Neurol Neurosurg 1980;82:269-72.

33. Liu LH, Huang RH. The complications of radiofrequency therapy for trigeminal neuralgia. Chin J Nerv Ment Dis (Chin) 2002;28:215-6.

34. Yang Y, Shao Y, Wang H, Liu Y, Zhu S, Wu C. Neuronavigation-assisted percutaneous thermocoagulation therapy in trigeminal neuralgia. Clin J Pain 2007;23:159-64.

35. Skirving DJ, Dan NG. A 20-year review of percutaneous balloon compression of the trigeminal ganglion. J Neurosurg 2001;94:913-7.

36. Shenouda EF, Coakham HB. Management of petrous endostosis in posterior fossa procedures for trigeminal neuralgia: Operative technique. Neurosurgery 2007;60: ONS63-9. 
37. Linskey ME, Jho HD, Jannetta PJ. Microvascular decompression for trigeminal neuralgia caused by vertebrobasilar compression. J Neurosurg 1994;81:1-9.

38. Singla V, Modi M, Singh P, Khandelwal NK. Dolichoectasia of vertebrobasilar system: A rare cause of tic douloureux. Indian J Med Sci 2007;61:30-1.

39. Baechli H, Gratzl O. Microvascular decompression in trigeminal neuralgia with no vascular compression. Eur Surg Res 2007;39:51-7.

40. Pamir MN, Zirh TA, Ozer AF, Keleş GE, Baykan N. Microvascular decompression in the surgical management of trigeminal neuralgia. Neurosurg Rev 1995;18:163-7.

41. Tronnier VM, Rasche D, Hamer J, Kienle AL, Kunze S. Treatment of idiopathic trigeminal neuralgia: Comparison of long-term outcome after radiofrequency rhizotomy and microvascular decompression. Neurosurgery 2001;48:1261-7.

42. Ashkan K, Marsh H. Microvascular decompression for trigeminal neuralgia in the elderly: A review of the safety and efficacy. Neurosurgery 2004;55:840-50.

43. Onoda K, Agari T, Date I. Microvascular decompression for trigeminal neuralgia in older patients. No Shinkei Geka 2008;36:45-9.

44. Sekula RF, Marchan EM, Fletcher LH, Casey KF, Jannetta PJ. Microvascular decompression for trigeminal neuralgia in elderly patients. J Neurosurg 2008;108:689-91.

45. Li N, Zhao WG, Pu CH, Shen JK. Clinical application of artificial dura mater to avoid cerebrospinal fluid leaks after microvascular decompression surgery. Minim Invasive Neurosurg 2005;48:369-72.

46. Park JS, Kong DS, Lee JA, Park K. Intraoperative management to prevent cerebrospinal fluid leakage after microvascular decompression: Dural closure with a "plugging muscle" method. Neurosurg Rev 2007;30:139-42.

47. Schaller B. Trigeminocardiac reflex: A clinical phenomenon or a new physiological entity? J Neurol 2004;251:658-65.

48. Schaller B, Probst R, Strebel S, Gratzl O. Trigeminocardiac reflex during surgery in the cerebellopontine angle. J Neurosurg 1999;90:215-20.

49. Schaller B. Trigemino-cardiac reflex during microvascular trigeminal decompression in cases of trigeminal neuralgia. J Neurosurg Anesthesiol $2005 ; 17: 45-8$.

50. Tatli M, Satici O, Kanpolat Y, Sindou M. Various. Surgical modalities for trigeminal neuralgia: Literature study of respective long-term outcomes. Acta Neurochir (Wien) 2008;150:243-55.

51. Kabatas S, Karasu A, Civelek E, Sabanci AP, Hepgul KT, Teng YD. Microvascular decompression as a surgical management for trigeminal neuralgia: Long-term follow-up and review of the literature. Neurosurg Rev 2009;32:87-94.

Accepted on 12-03-2009

Source of Support: Nil, Conflict of Interest: None declared. 